\title{
STRESS INTENSITY FACTOR ANALYSIS AND FATIGUE BEHAVIOR OF A CRACK IN THE RESIDUAL STRESS FIELD OF WELDING
}

\author{
Hiroyuki Terada \\ Japan Aerospace Technology Foundation, \\ Tokyo, Japan
}

\begin{abstract}
This paper deals with the behavior of a crack in the residual stress field induced by the butt weld in a wide plate.

It is known that the distribution form of residual stress has similarities regardless of the welding process, although the size and the magnitude of the residual stress depend largely on the welding process.

Stress intensity factor and stress redistribution induced by the crack extension were calculated for a crack with arbitrary length and location. The stress redistributions caused by crack extension obtained by the present analysis showed good agreement with the experimental data.

Fatigue crack propagation behavior in the residual stress field reported by Glinka was also examined from $\Delta K$ point of view. The effect of residual stress on the fatigue crack propagation rate is considered to be the effect of varying mean stress. It was shown that fatigue crack propagation rate is estimated by the following equation with reasonable accuracy.

$$
\frac{d a}{d n}=C \Delta K^{\alpha}\left(1+\frac{\sigma_{0}}{\Delta \sigma} F_{r e s}\right)
$$
\end{abstract}

In the above equation, material constants $C$ and $\alpha$ of Paris's law are experimentally obtained by using specimens without the weld joint.

Keywords: stress intensity factor analysis, crack, residual stress field, butt weld, stress redistribution, fatigue crack, crack propagation

\section{INTRODUCTION}

The importance of the effects of residual stress on the fatigue and fracture strength of the welded joints of many machine parts and structural components has been recognized alongside that of material deteriorations by heat ingestion by welding. Consequently, many experimental studies on fatigue crack propagation behaviors or fracture strength and some analytical works for welded joints have been carried out. References [1] and [2] list major summaries on those works. However, studies relating stress analysis and experimental results seem to be few [3], [4], since the variation of residual stress or redistribution due to crack extension are considered to make the problem complicated.

In the present paper, stress analysis of a crack perpendicular to the welding bead by the butt weld in a wide plate was carried out using the Green function method. The distribution functions proposed by the author [5] as well as Tada and Paris [6], both of which satisfy all the physical 
conditions of the residual stress by welding, were employed in the analysis. Even when the stress relieving treatment is conducted, the residual stress induced by welding cannot be removed completely. And as a result, some residual stress, the distribution form of which is more or less similar to that of as-weld condition, remains. Hence the present results are also applicable to the stress relieved joints as well as the as weld joints, regardless of a welding method, i.e. either by gas tungsten arc welding, electron beam welding or friction stir welding.

\section{STRESS INTENSITY FACTOR ANALYSIS}

As for the distribution form of the residual stress by welding, the author [5] proposed equation (1) to simulate $\sigma$ as shown in Fig. 1.

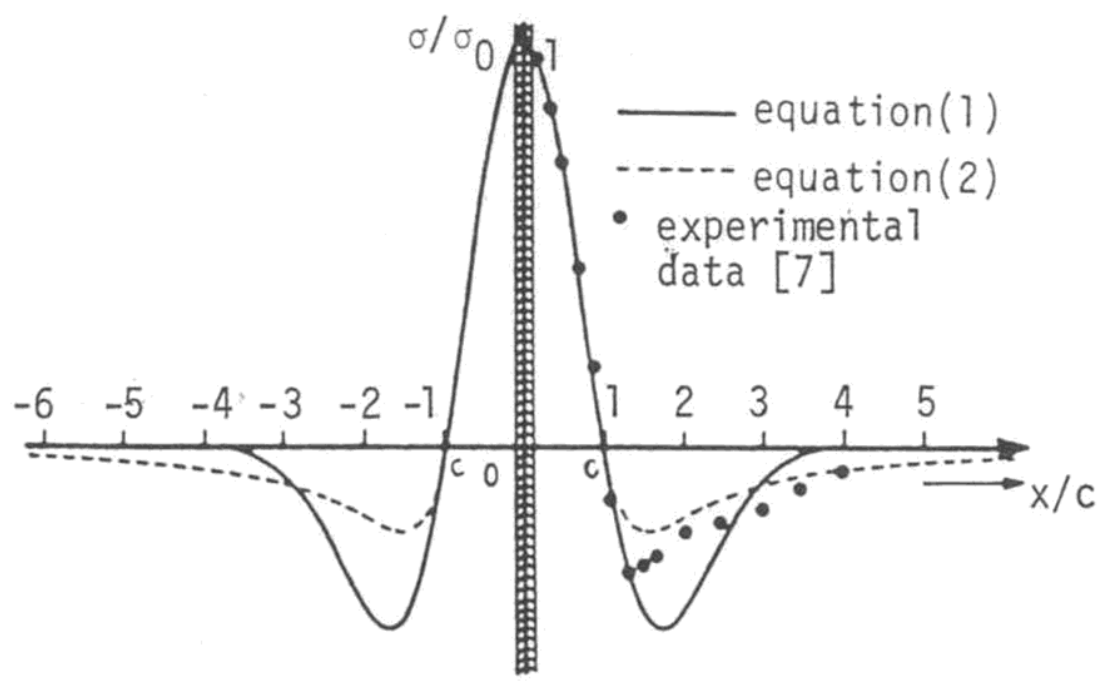

Fig. 1. Residual stress distribution by welding and its assumed functions

$$
\sigma_{y}(x)=\sigma_{0} e^{-0.5 x^{2}}\left(1-x^{2}\right)
$$

where, $\sigma_{0}$ is the maximum residual stress at the center line of welding.

Equation (1) satisfies all the physical conditions of residual stress which would be induced by the butt weld of the infinite plate. Another equation satisfying those conditions was proposed by Tada and Paris [6] as shown by equation (2).

$$
\sigma_{y}(x)=\sigma_{0}\left(1-x^{2}\right) /\left(1+x^{4}\right)
$$

It is also shown by the dashed line in Fig. 1. In the Fig., "c" is the characteristic length defined as the distance from the weld center line to the point where the original residual stress form changes its sign from tension to compression.

The selection of either equation (1) or (2) as the distribution function depends mainly on the observed form of the compression side of residual stress for each case.

The residual stress distribution measured by Kanazawa et al. [7] is also presented in Fig. 1. Their experimental data in the compressive stress region drop between the simulation curves given by equations (1) and (2).

Once the distribution function is defined, the stress intensity factor $\mathrm{K}$ is calculated by equation (3). 


$$
K \pm a=\frac{1}{\sqrt{\pi a}} \int_{-a}^{a} \sigma_{y}(\xi) \sqrt{\frac{a \pm \xi}{a \mp \xi}} d \xi
$$

For a symmetric crack, the stress intensity factor is evaluated by substituting equation (1) or (2) with equation (3). For the general case where the crack is eccentric to the welded line as shown in Fig. 2, the stress intensity factor is calculated by replacing $\mathrm{x}$ with $(\mathrm{x}+\mathrm{L})$ in $\sigma_{y}$ equations [8].

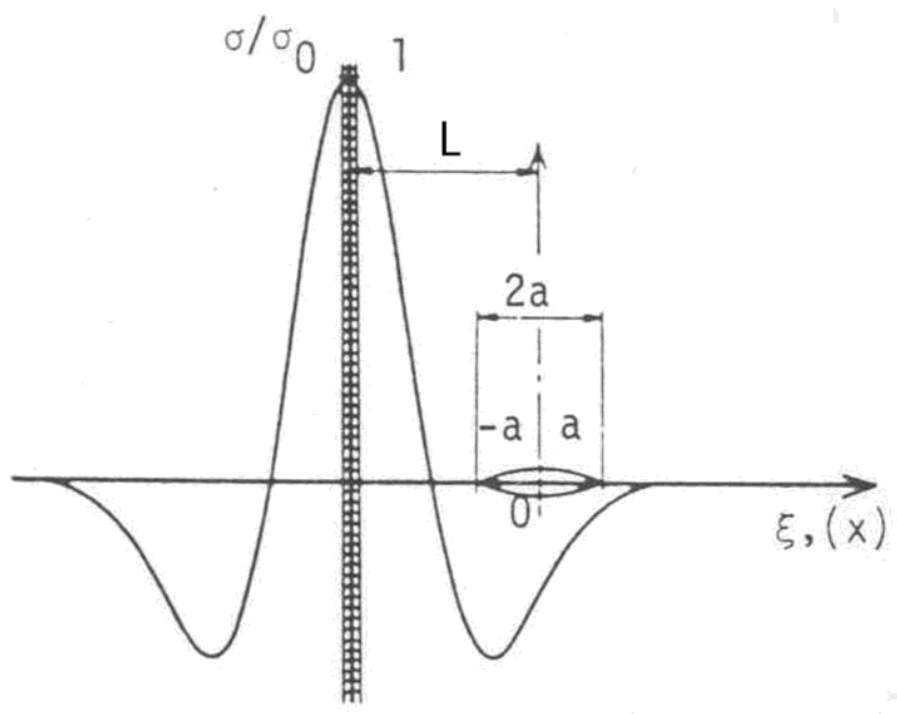

Fig. 2. Eccentric crack in the residual stress field by welding

Here, $\mathrm{L}$ is the distance between the welded line and center of a crack normalized by the characteristic length "c" of the original stress distribution. The evaluation of equation (3) is conducted by using the following numerical integration formula [9].

$$
\int_{-a}^{a} \sigma_{y}(\xi) \sqrt{\frac{a \pm \xi}{a \mp \xi}} d \xi=2 a \sum_{i=1}^{n} w_{i} \sigma_{y}\left(y_{i}\right)
$$

where, $y_{i}=\mp a\left(1-2 x_{i}\right) ; w_{i}=\frac{2 \pi x_{i}}{2 n+1} ; x_{i}=\cos ^{2}\left(\frac{(2 i-1) \pi}{2(2 n+1)}\right)$

\section{STRESS REDISTRIBUTION BY CRACK EXTENSION}

As a matter of course, the existence of a crack in the residual stress field disturbs the original distribution indicated by equations (1) or (2) in the vicinity of the crack. Away from the crack, the stress distribution may not change much from the original distribution form. The redistributed stress normal to the crack line, $\sigma_{\mathrm{y}, \mathrm{re}}$ is evaluated by equation (5), using the Principle of Stress Superposition.

$$
\sigma_{\mathrm{y}, \mathrm{re}}(x)=\sigma_{y}(x)+\frac{a}{\pi \sqrt{x^{2}-a^{2}}} \int_{-a}^{a} \sigma_{y}(\xi)\left\{\frac{\sqrt{a^{2}-\xi^{2}}}{x-\xi}+\frac{\sqrt{a^{2}-\xi^{2}}}{x+\xi}\right\} d \xi
$$


In the above equation, $\sigma_{y}(x)$ is the original residual stress distribution without a crack.

Equation (5) is evaluated by the following numerical integration formula with sufficient accuracy for any crack length and eccentricity [10].

$$
\int_{-a}^{a} \sigma_{y}(\xi) \frac{\sqrt{a^{2}-\xi^{2}}}{x \pm \xi} d \xi=a^{2} \sum_{i=1}^{n} w_{i} \frac{\sigma_{y}\left(a t_{i}\right)}{x \pm a t_{i}}
$$

Where, $t_{i}=\cos \frac{i \pi}{n+1}, w_{i}=\frac{\pi}{n+1} \sin ^{2}\left(\frac{i \pi}{n+1}\right)$

\section{RESULTS AND DISCUSSION}

The convergence of the numerical integrations of equations (4) and (6) is rapid for a wide range of crack sizes and eccentricity. Numerical results for the distribution function (1) converge faster than equation (2). However, 10 to 20 terms of the polynomials of the numerical integration were sufficient to obtain the 5 figure accuracy for both functions.

\subsection{Numerical Results of Stress Intensity Factor Analysis}

As one of the calculation results, the relation of crack eccentricity and stress intensity factor of a crack with constant length is presented in Fig. 3.

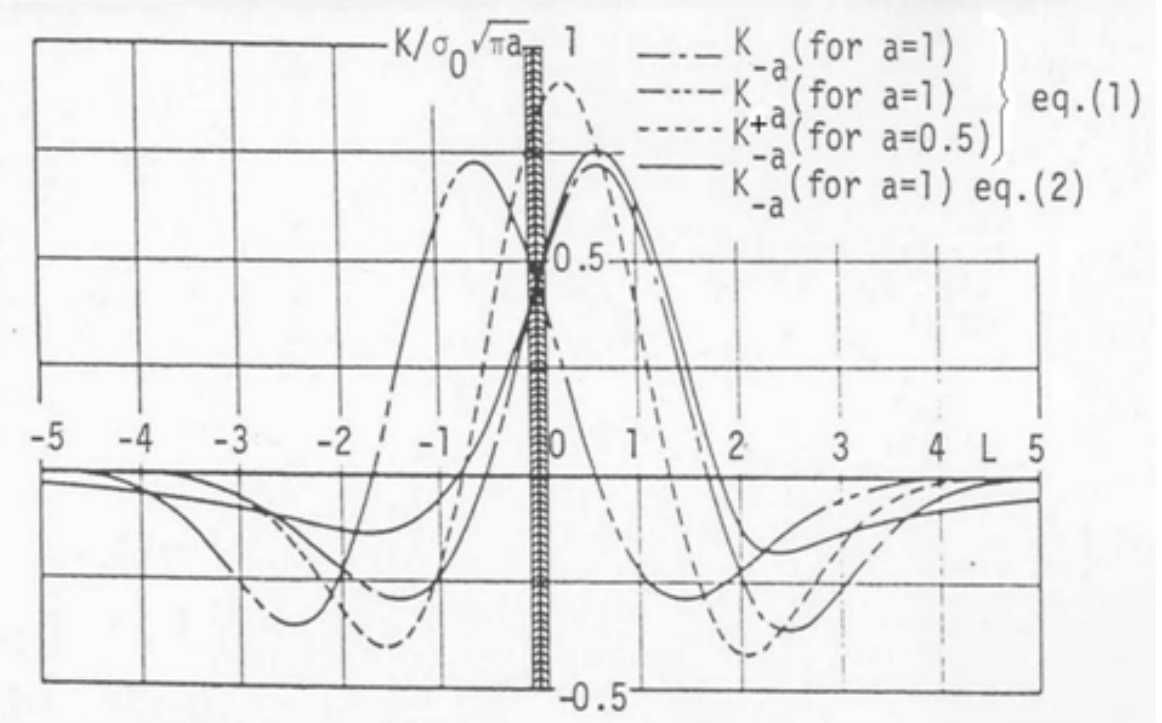

Fig. 3. Effect of crack eccentricity on $\mathrm{K}$ (constant crack length)

It should be noted that the maximum value is not attained at $\mathrm{L}=0$ for the same crack size. Stress intensity factor becomes maximum when one of the crack tip has just crossed the welded line, namely, in that case the crack tip is surrounded by the higher stress of the original distribution. The stress intensity factors for a crack with various sizes and eccentricities are presented in Fig. 4 and 5 for distribution functions (1) and (2), respectively. In Fig. 4 and 5, stress intensity factor $K$ is defined by the following equation.

$K=\sigma_{0} \sqrt{\pi a} F_{r e s}$ 
where, $F_{\text {res }}$ is the correction factor related to the residual stress

The solid line indicates the stress intensity factor for the crack tip near the welded joint, while the dashed line corresponds to the remote side tip of the crack. The negative stress intensity factor becomes meaningful when we consider the crack tip opening level $\left(\sigma_{o p}\right)$ under additional tensile fatigue load. It may elevate the level of $\sigma_{o p}$. As a result, fatigue crack growth rate may decrease in that area.

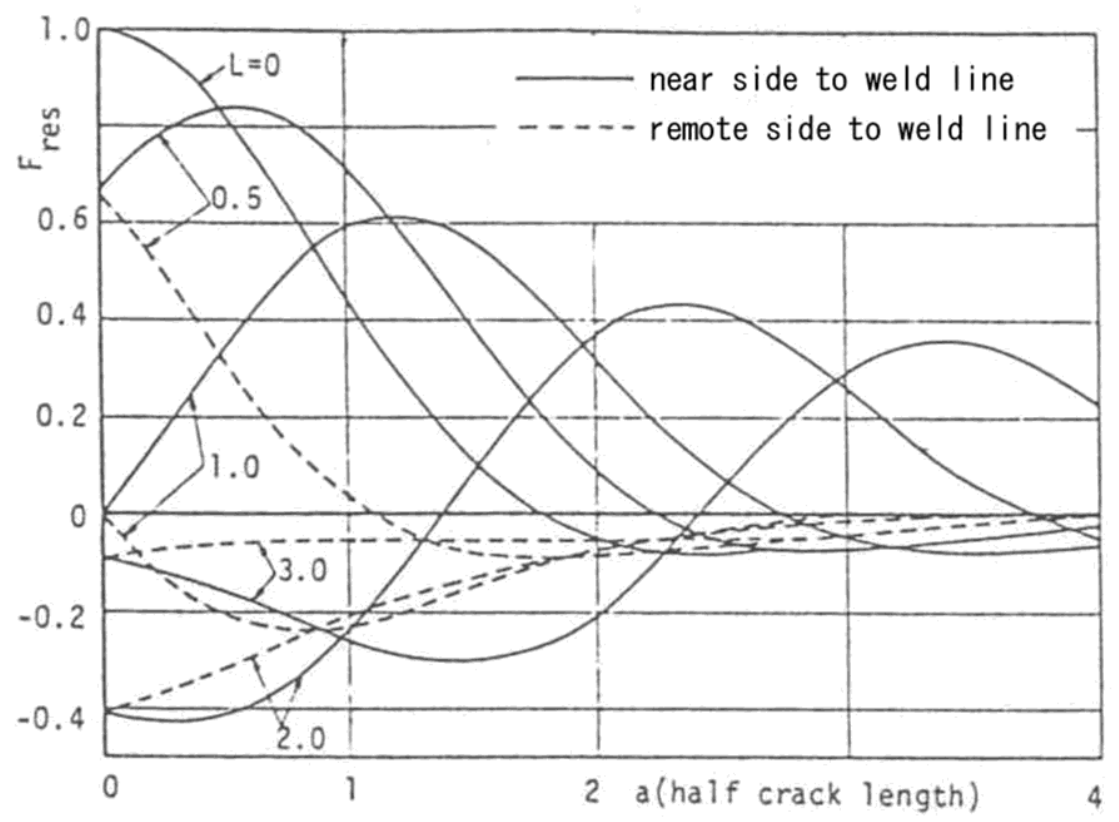

Fig. 4. Relation of stress intensity factor, crack size and eccentricity [equation (1)]

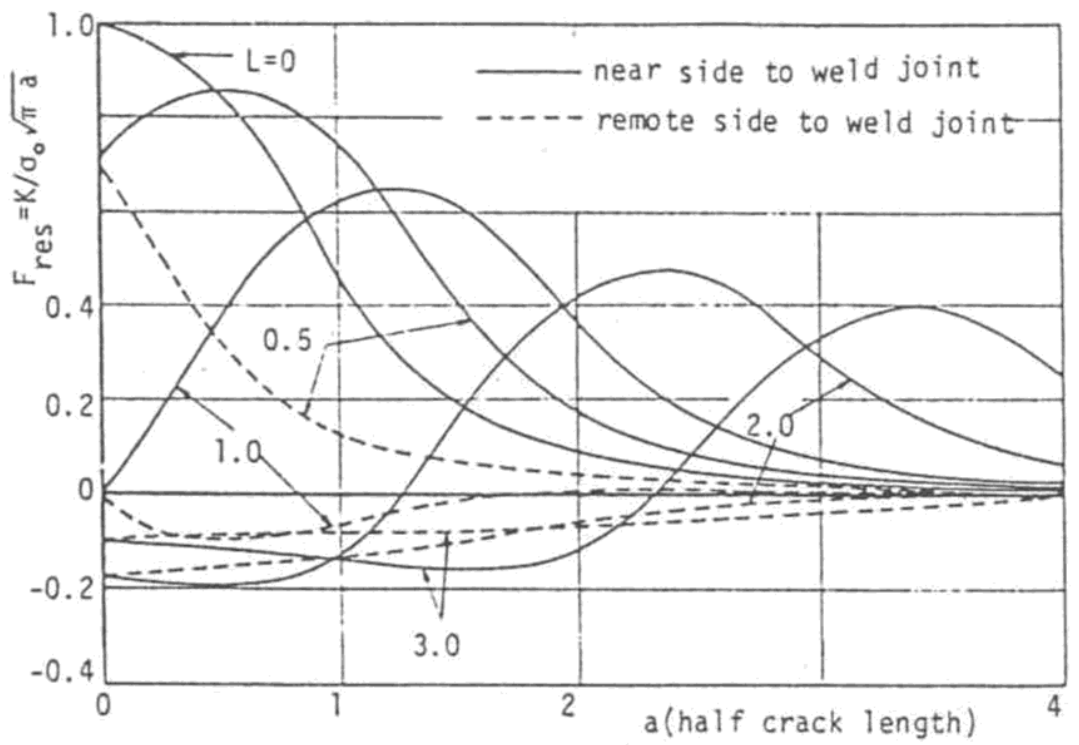

Fig. 5. Relation of stress intensity factor, crack size and eccentricity [equation (2)] 


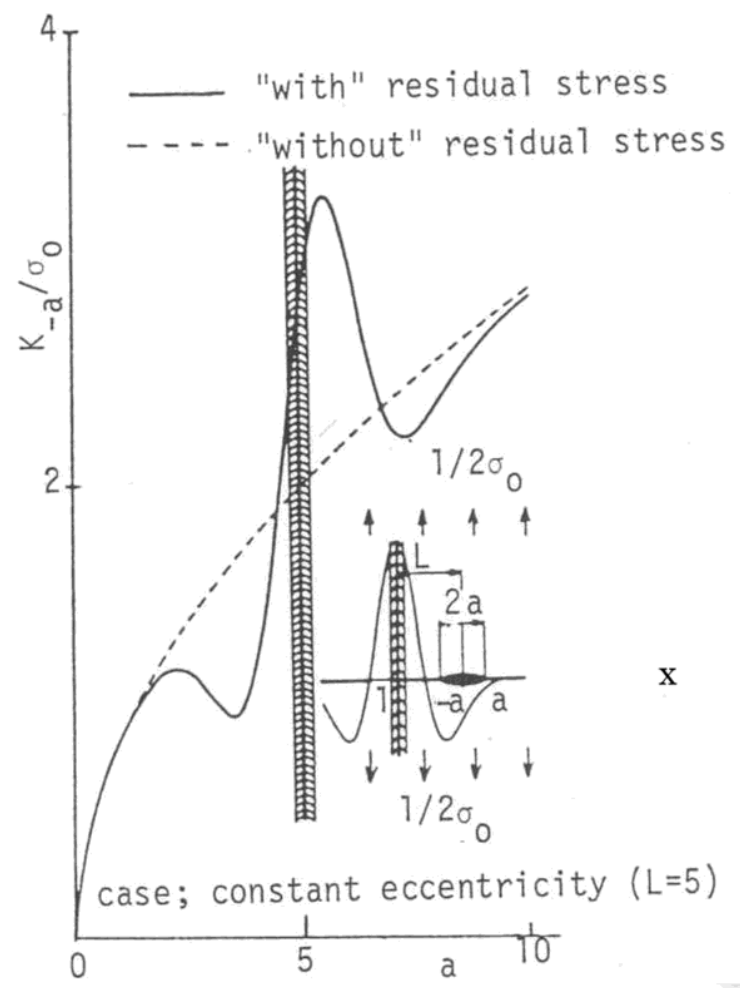

Fig. 6. K for a crack approaching welded joint

Another example demonstrating the effect of residual stress on the stress intensity factor for an extending crack with constant L was shown in Fig. 6. In that case, remotely applied fatigue stress $\Delta \sigma$ was assumed as $1 / 2$ of $\sigma_{0}$ (maximum residual stress at weld line).

When the residual stress does not exist, the stress intensity factor increases monotonically as indicated by the dashed line. On the other hand, when the residual stress exists, the stress intensity factor whips as the crack tip approaches and crosses the welding line. 


\subsection{Stress Redistribution by Crack Extension}

Fig. 7 and 8 demonstrate the redistribution of $\sigma_{y, r e}$ along the crack axis for a symmetric and an eccentric crack, respectively.

The evaluation of equation (5) was carried out by using distribution function equation (2). In Fig. 7 and $8, \lambda$ is the crack length normalized by characteristic length "c".

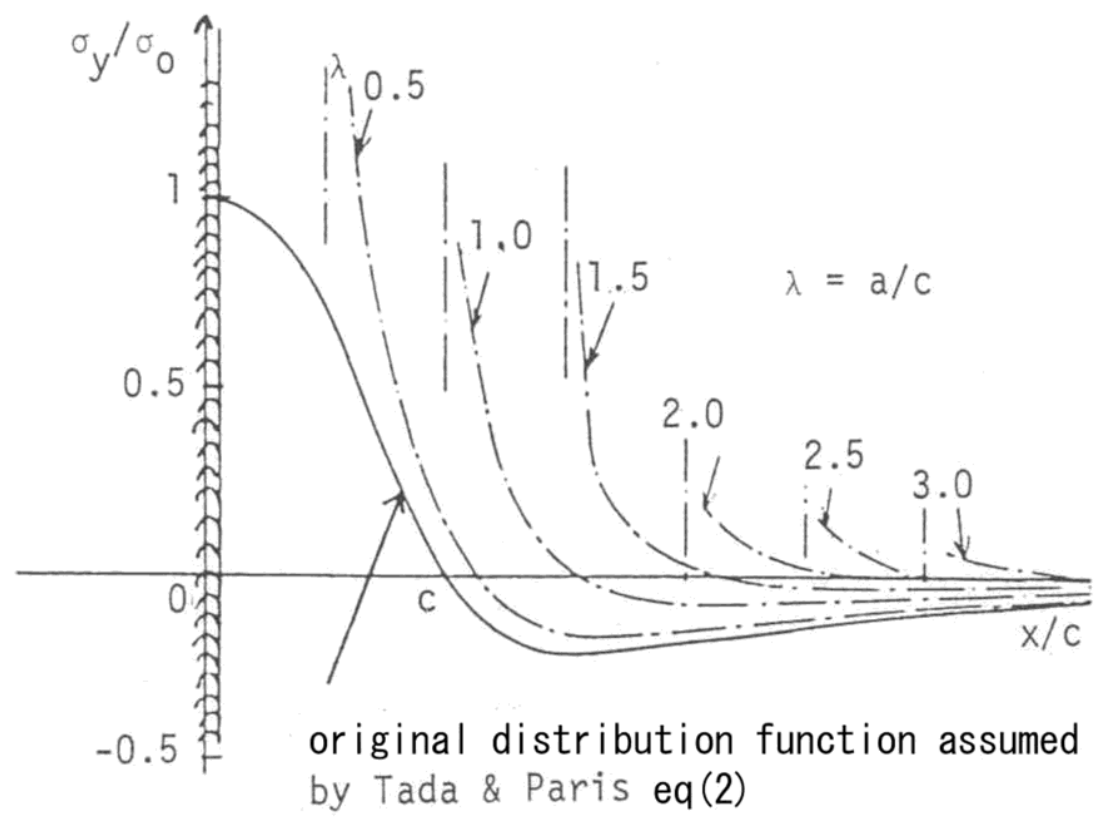

Fig. 7. Crack extension and redistribution of $\sigma_{y}(L=0$; symmetric crack $)$

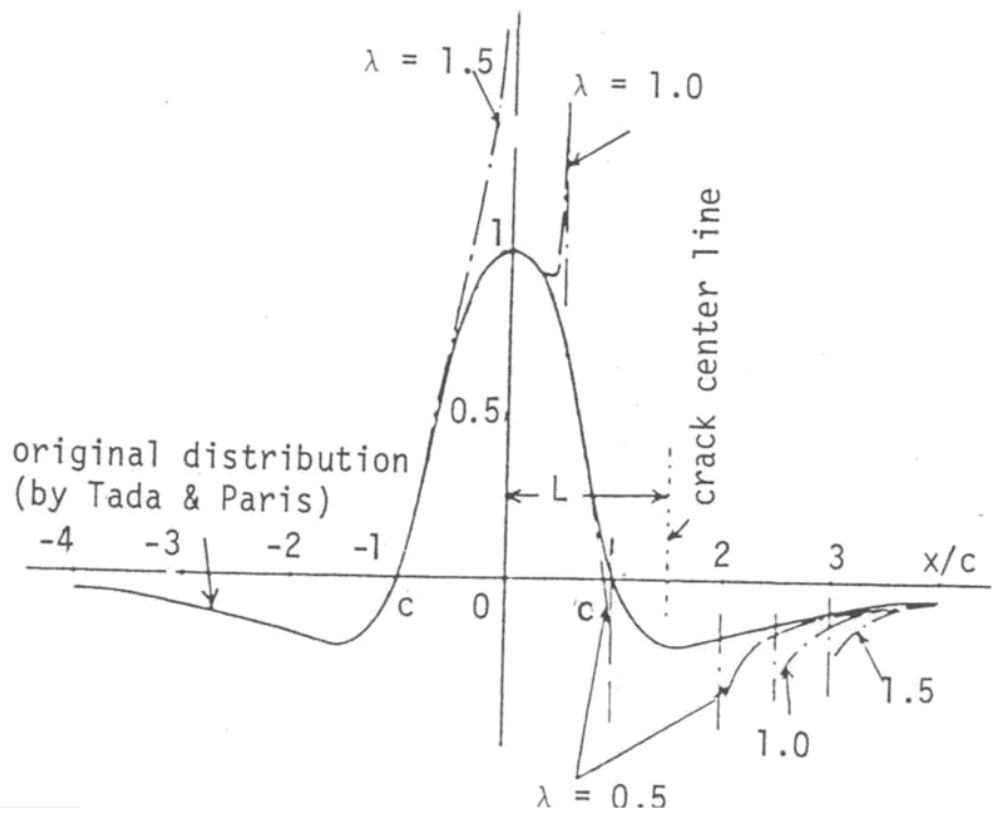

Fig. 8. Crack extension and redistribution of $\sigma_{y}(L=1.5$; eccentric crack)

Stress redistribution form for the symmetric crack in the residual stress field was observed by Kanazawa et al. [7]. Fig. 9 shows the experimental results obtained by measuring the released strain with extending the saw cut. Though analytical results presented in Fig. 7 are calculated for the infinite plate, good correlation is observed with the experimental data. 


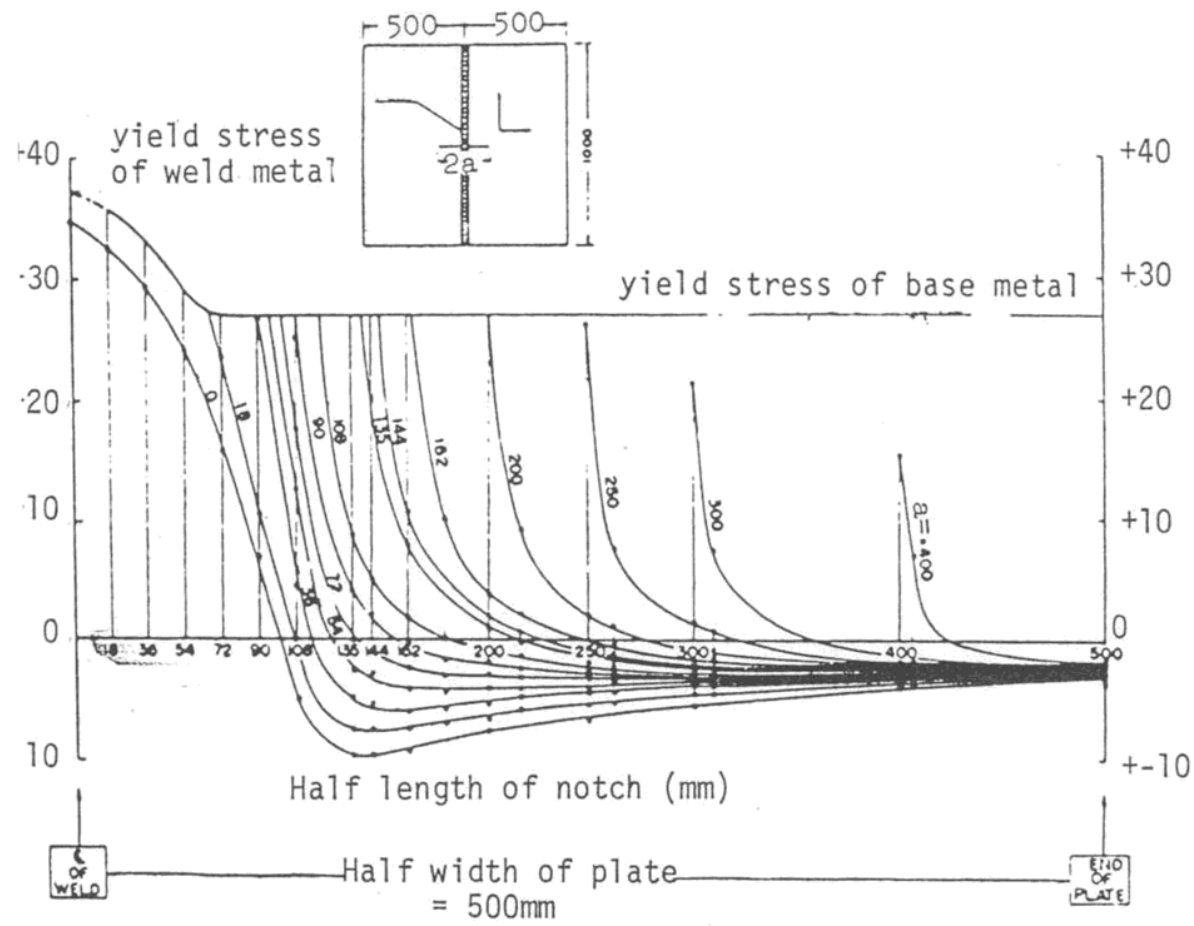

Fig. 9. Effect of notch length on residual stress redistribution of the specimen with longitudinal weldment [7]

\subsection{Effect of Residual Stress on Fracture Toughness and Fatigue Crack Propagation}

It is obvious that the residual tensile stress brings about unfavorable effect on fatigue crack propagation behavior as well as on fracture strength of the welded joints as might be anticipated from the results shown in Fig. 6.

When we consider the fracture strength of the welded plate with a crack subjected to static load, fracture toughness $\left(K_{c}\right)$ is evaluated by equation (7).

$$
K_{c}=\sigma_{c} \sqrt{\pi a_{c}}\left(1+\frac{\sigma_{0}}{\sigma_{c}} F_{r e s}\right)
$$

where, $F_{\text {res }}$ is the correction factor due to residual stress, and is presented in fig.s 3, 4 and 5 for various locations of the crack, $\sigma_{0}$ is the maximum residual stress by welding and, $\sigma_{c}$ is the remotely applied critical stress.

It would be reasonable to consider that the fatigue crack growth rate is considered primarily a function of $\Delta K$ and the effect of residual stress was accounted to be just a secondary factor. In this study it is accounted by a correction factor to Paris's Law as shown in the following manner.

$$
\begin{aligned}
& \frac{d a}{d n}=C \Delta K^{\alpha} F_{1} \\
& F_{1}=1+\frac{\sigma_{0}}{\Delta \sigma} F_{r e s} \\
& \Delta K=\Delta \sigma \sqrt{\pi a} F_{2}
\end{aligned}
$$

where, $\Delta \sigma$ is remotely applied fatigue stress, and $F_{1}$ and $F_{2}$ are the correction factors related to the residual stress and geometry of the cracked plate, respectively. 
Glinka [11] studied the fatigue crack growth rate of a symmetric crack perpendicular to the weld line. His results both for "with" and "without" residual stress are presented in Fig. 10, together with two prediction curves discussed by Nelson [3]. One of the predictions is based on the crack closure model. In Nelson's paper, the value of crack opening ratio "q" was directly referred from the results by Newman [12]. The crack closure model gives good estimation, but the results may greatly depend on the accuracy of "q", and it is generally not easy to obtain the correct q for each material and testing. The singular points of the prediction curves by the superposition approach, which might have arose from the insufficient simulation of the residual stress, observed in Fig. 10, are also problematic because the actual stress distribution, and hence the stress intensity factor, has no singular properties as indicated in Fig. 1.

In the present study, for simplicity, the author assumed the following Paris type equation for the experimental results given in Fig. 10, since the data corresponded to "without" residual stress can be simulated by straight lines in the log-log diagram for the range shown in the Fig..
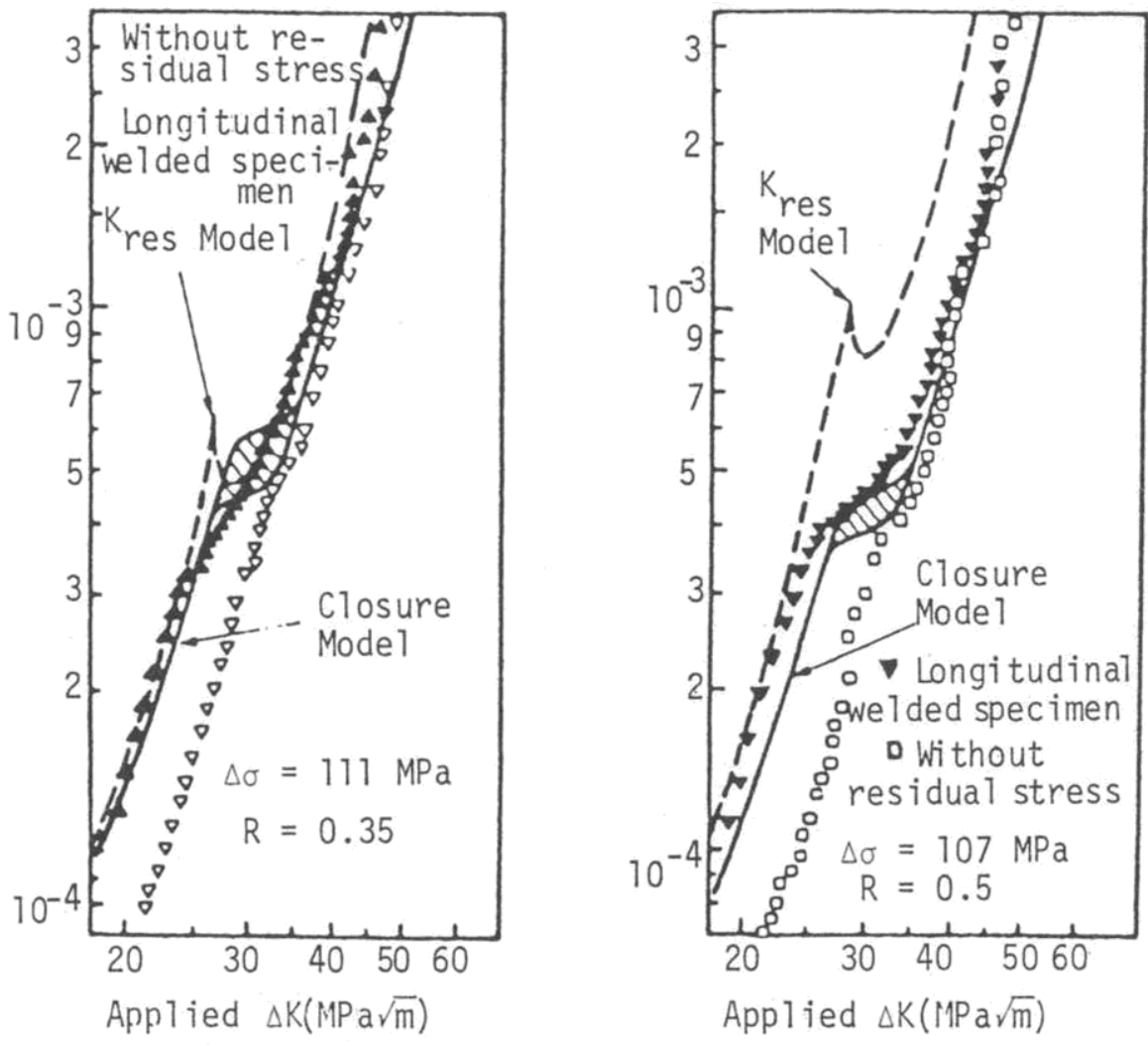

Fig. 10. Comparison of crack growth rate predicted by a superposition approach and by a simple closure model with experimental data [11]

Material constants $\mathrm{C}$ and $\alpha$ in equation (8) are determined from the experimental data of the specimens "without" residual stress (open symbols). In Fig. 10, they are obtained as $C=6.14 \times 10^{-11}$ and $\alpha=4.5$ for $\mathrm{R}$ (stress ratio) $=0.5$, and $\mathrm{C}=1.36 \times 10^{-10}$ and $\alpha=4.3$ for $\mathrm{R}=0.35$, respectively. The straight solid lines are those evaluated by using these material constants.

When we consider the effect of residual stress, we must evaluate $F_{1}$ in equation (8). The residual stress distribution in this case is reported as Fig. 11 [12]. The maximum $\sigma_{y}$ at the weld center line i.e. $\sigma_{0}(=210 \mathrm{MPa})$ and the abscissa of transition point $(\mathrm{x}=20 \mathrm{~mm})$ were adopted to evaluate $F_{1}$. Equation (2) was used to calculate the correction factor for residual stress $F_{\text {res. }}$.

The results are presented by the dashed curves in Fig. 12. These curves show good estimation of the effect of residual stress on the behavior of the fatigue crack propagation. 


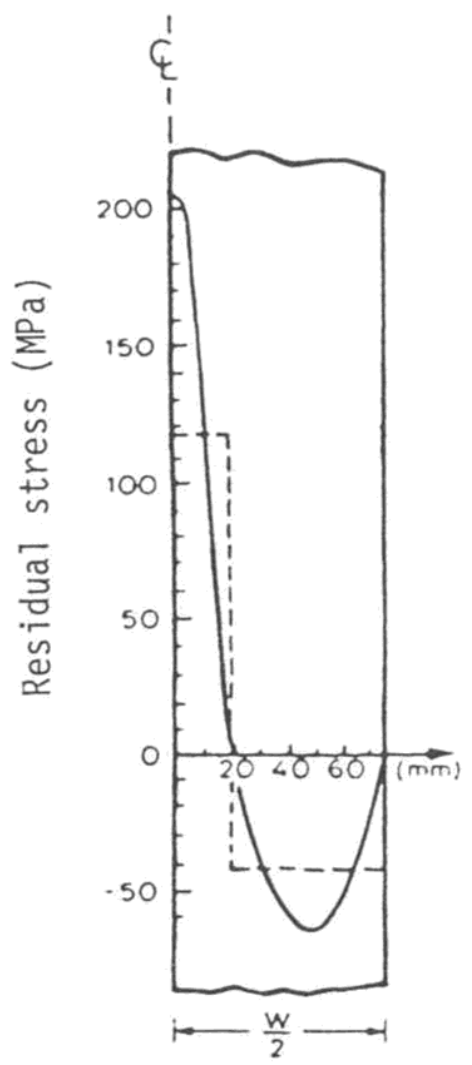

Fig. 11. Residual stress distribution [11]

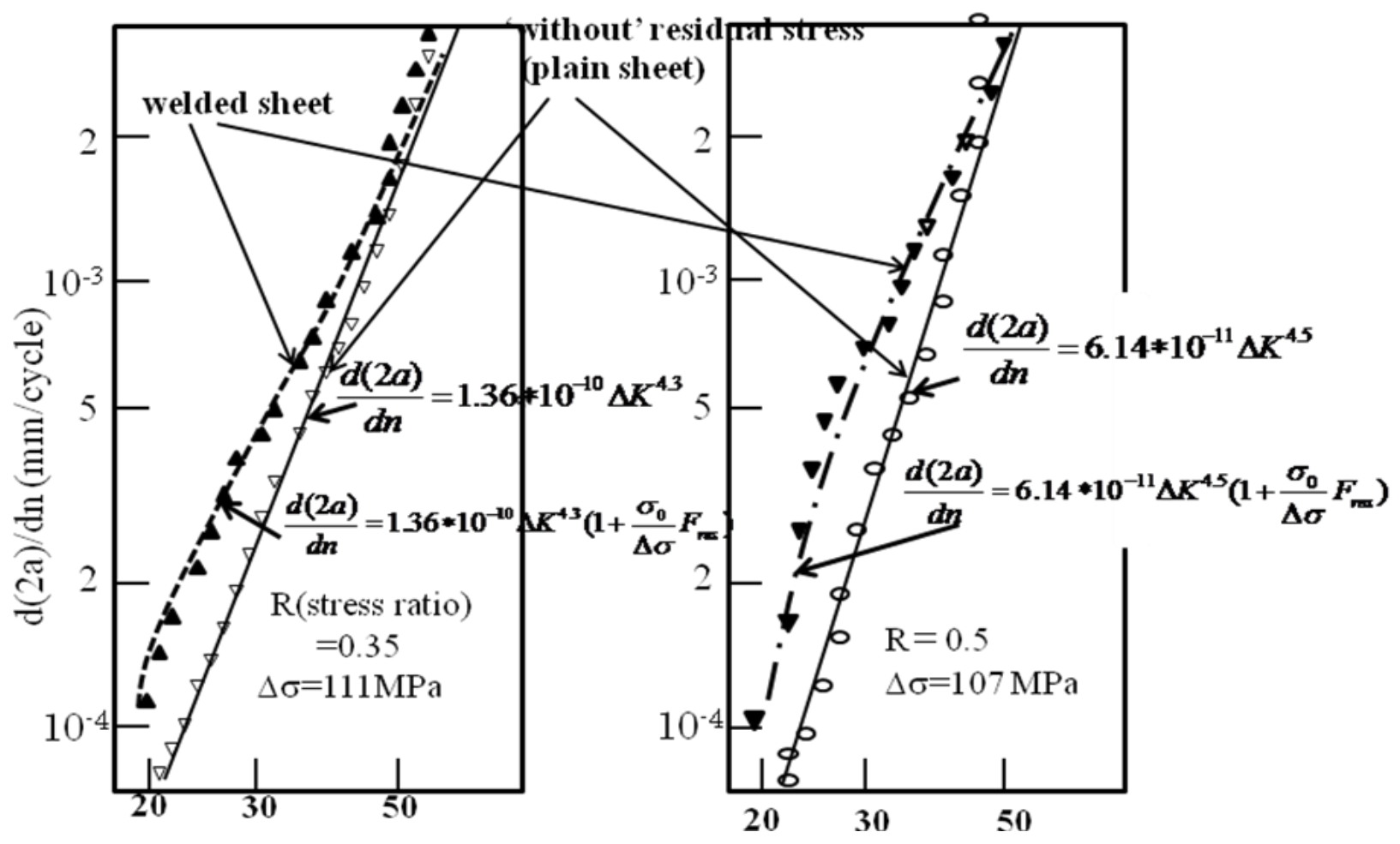

Fig. 12. Comparison of crack growth rate estimated by present method with experimental data [11]

Equation (8) and Figure 12 suggest that the effect of residual stress is that of mean stress, which is not constant but a function of $\mathrm{x}$ that is expressed by the original distribution form. 


\section{CONCLUDING REMARKS}

The crack problem in the residual stress field was discussed analytically. And the results of the present study are summarized as follows.

1. Stress intensity factors of a crack perpendicular to the weld joint are obtained for various sizes and eccentricities.

2. Stress redistribution induced by the crack extension is also analyzed using the Principle of Stress Superposition. The results showed good correlation with the experimental data.

3. The effect of residual stress on the fatigue crack propagation was examined using the analytical results obtained in this paper. The crack propagation rates were shown by the following formula, using the material constants $\mathrm{C}$ and $\alpha$ obtained by the fatigue crack propagation test of the parent material.

$$
\begin{aligned}
& \frac{d a}{d n}=C \Delta K^{\alpha} F_{1} \\
& F_{1}=1+\frac{\sigma_{0}}{\Delta \sigma} F_{r e s}
\end{aligned}
$$

The effect of residual stress on the fatigue crack propagation is compared to that of mean stress varying with co-ordinate $\mathrm{x}$.

\section{REFERENCES}

[1] Hoeppner, D.W. (1978). Fatigue Testing of Weldments. American Society for Testing and Materials STP 648.

[2] Throop, J.F. \& Reemsnyder, H.S. (1982). Residual Stress Effects in Fatigue. American Society for Testing and Materials STP 776.

[3] Nelson, D.V. (1982). Effects of Residual Stress on Fatigue Crack Propagation. American Society for Testing and Materials STP 776, (pp. 172 - 188).

[4] Parker, A.P. (1982). Discussion to ref (3). American Society for Testing and Materials STP 776, (pp. 188 - 194).

[5] Terada, H. (1976). An Analysis of the Stress Intensity Factor of a Crack Perpendicular to the Welding Bead. Engineering Fracture Mechanics. 8(3), 441 - 444.

[6] Tada, H. \& Paris, P.C. (1983). The Stress Intensity Factor for a Crack Perpendicular to the Welding Bead. International Journal of Fracture. 21(2), 279 - 284.

[7] Kanazawa, T., Oba, H. \& Susei, S. (1962). The Effect of Welding Residual Stress Upon Brittle Fracture Propagation (Rept. 2). Transactions of Japan Society of Naval Architects. No. 110, 359 - 368.

[8] Terada, H. \& Nakajima, T. (1985). Analysis of Stress Intensity Factor of a Crack Approaching Welding Bead. International Journal of Fracture. Vol. 27, 83 - 90.

[9] Abramowitz, M. \& Stegun, A. (1954). Handbook of Mathematical Function. Dover ed. p. 890.

[10] ibid., p. 889.

[11] Glinka, G. i inni. (1979). Fracture Mechanics. American Society for Testing and Materials STP 677. (pp. 198 - 212).

[12] Newman, J.C., Jr. (1981). A Crack Closure Model for Predicting Fatigue Crack Growth Under Aircraft Spectrum Loading. NASA. (TM 81941) 